\title{
Intact priming of words and nonwords in amnesia
}

\author{
FRANK HAIST \\ University of California, San Diego, California \\ and San Diego State University, San Diego, California \\ and \\ GAIL MUSEN and LARRY R. SQUIRE \\ Veterans Affairs Medical Center, San Diego, California \\ and University of California, San Diego, California
}

\begin{abstract}
Amnesic patients and control subjects studied words and nonwords and were then given a perceptual identification test involving briefly presented new (i.e., unstudied) and old (i.e., previously studied) items. Perceptual priming was measured as an increase in the probability of identifying previously studied items in comparison with new items. Amnesic patients exhibited entirely normal priming for both old words and old nonwords. The amnesic patients were significantly impaired, however, in recognizing the items that had appeared on the perceptual identification test. The priming of nonwords did not appear to be based on the activation of words that were phonologically or orthographically similar to the nonwords (i.e., the effect was not based on neighborhood effects). The results for nonwords therefore suggest that priming can involve the acquisition of new information, not simply the activation of preexisting representations. Perceptual priming is proposed to reflect specific changes in early-stage processing systems that operate prior to and independently of the systems required for establishing declarative memory.
\end{abstract}

Experimental studies suggest that memory is not a single entity but is composed of multiple separate systems (Hintzman, 1990; Moscovitch, 1982; Richardson-Klavehn \& Bjork, 1988; Schacter, 1987; Squire, 1982; Tulving, 1985; Weiskrantz, 1987). Normal subjects exhibit dissociations in performance between tasks that require conscious recollection of past events or facts and tasks that access memory indirectly. Amnesic patients provide particularly compelling evidence for this dissociation. These patients are severely impaired on tests of declarative (explicit) memory that assess memory for recently learned facts or episodes. Nevertheless, they perform entirely normally on tests of nondeclarative (implicit) memory that assess skill learning (Brooks \& Baddeley, 1976; Cohen \& Squire, 1980; Musen, Shimamura, \& Squire, 1990; Nissen \& Bullemer, 1987; Squire \& Frambach, 1990), judgments and preferences influenced by recent encounters with stimuli (Johnson, Kim, \& Risse, 1985; Squire \& McKee, in press), adaptation-level effects (Benzing \& Squire,

Preparation of this article was supported by the Medical Research Service of the Department of Veterans Affairs, the National Institute of Mental Health (NIMH) Grant MH24600, the Office of Naval Research, the McKnight Foundation, and an NIMH postdoctoral fellowship to Gail Musen (MH09858). The authors would like to thank Joyce Zouzounis and Kathleen Fuchs for research assistance. F. Haist, G. Musen, and L. R. Squire are all in the Department of Psychiatry at the University of California, San Diego. Correspondence concerning this article should be addressed to Larry R. Squire, Veterans Affairs Medical Center (V116a), 3350 La Jolla Village Drive, San Diego, CA 92161.
1989), and priming (Schacter, 1985, 1990; Shimamura, 1986; Tulving \& Schacter, 1990). Declarative memory depends on the integrity of the structures damaged in amnesia, especially the hippocampal formation and adjacent cortical structures (Squire \& Zola-Morgan, 1991), midline diencephalic structures (Butters \& Stuss, 1989; Graff-Radford, Tranel, Van Hoesen, \& Brandt, 1990; Shimamura, Jernigan, \& Squire, 1988), and basal forebrain (Damasio, Graff-Radford, Eslinger, Damasio, \& Kassell, 1985). In contrast, nondeclarative memory is independent of these structures.

One of the best studied examples of nondeclarative memory is repetition priming, which refers to an improved facility for identifying or detecting perceptual objects as a result of their recent presentation. For example, repetition priming can be measured as an improvement in the accuracy or as a reduction in the response time with which previously presented stimuli are identified. One view of repetition priming has been that facilitated performance is based on modifications of preexisting memory representations (Diamond \& Rozin, 1984; Mandler, 1980; Morton, 1969, 1979; Scarborough, Cortese, \& Scarborough, 1977). Thus, presentation of an item activates a preexisting representation of that item. Activation acts to reduce the threshold required for subsequent processing. This view received support from findings with the lexical decision task that normal subjects did not exhibit priming for novel material such as nonwords (i.e., pronounceable letter strings) that have no preexisting representation. In the lexical decision task, in which subjects must rapidly 
decide whether letter strings are real words or nonwords, robust priming has consistently been found for words, whereas priming has often been either reduced or absent for nonwords (Bentin \& Moscovitch, 1988; KersteenTucker, 1991; Scarborough et al., 1977; but see Monsell, 1985; Smith \& Oscar-Berman, 1990).

Recently, the activation view has been challenged by reports that normal subjects can in fact exhibit priming of novel material, that is, stimuli that have no preexisting representation. For example, studies with normal subjects have found priming for nonwords in a perceptual identification paradigm (Cermak, Talbot, Chandler, \& Wolbarst, 1985; Cermak, Verfaellie, Milberg, Letourneau, \& Blackford, 1991; Feustel, Shiffrin, \& Salasoo, 1983; Jacoby, 1983a; Jacoby \& Dallas, 1981; Rueckl, 1990; Salasoo, Shiffrin, \& Feustel, 1985; Whitlow \& Cebollero, 1989). Similarly, priming for nonverbal material has been found with line patterns (Musen \& Treisman, 1990) and novel objects (Schacter, Cooper, \& Delaney, 1990). In these cases, priming could be dissociated from recognition memory. Such findings have led to an alternative explanation that priming involves the creation of new information, not the activation of preexisting information. For example, priming has been proposed to reflect modifications in early-stage perceptual systems that are specific to the material being presented (Schacter, 1990; Tulving \& Schacter, 1990).

Studies done with amnesic patients could provide particularly strong evidence for the proposal that priming occurs for novel material as well as for familiar material, because amnesic patients are unlikely to engage in explicit memory strategies. Accordingly, a finding that amnesic patients perform entirely normally in a priming paradigm cannot be explained by supposing that the performance measure has been contaminated by explicit memory. Several recent studies suggest that amnesic patients can acquire novel nonverbal information implicitly (Gabrieli, Milberg, Keane, \& Corkin, 1990; Musen \& Squire, 1991a; Schacter, Cooper, Tharan, \& Rubens, 1991). For example, amnesic patients were able to classify drawings of novel objects that they had studied only once previously more quickly than they were able to classify drawings that they had not studied previously (Schacter et al., 1991). In addition, in studies of reading speed, amnesic patients acquired at a normal rate the ability to read repeated nonwords (Musen \& Squire, 1991b). Furthermore, Squire \& McKee (in press) found that amnesic patients exhibit the normal bias of judging previously presented names as famous. The facilitatory effect of prior encounters on fame judgments was as great for nonfamous names as it was for famous names.

In contrast with the studies just cited, other studies have reported that amnesic patients cannot acquire novel information implicitly (Cermak et al., 1985; Cermak et al., 1991; Diamond \& Rozin, 1984). However, in these cases, which involved tests with nonwords, it has remained possible that the failure of amnesic patients to perform as well as normal subjects was due to normal subjects' employ- ing explicit memory strategies rather than to amnesic patients' failing to exhibit implicit memory. In one study (Cermak et al., 1985), amnesic patients and control subjects were presented with 10 words or nonwords for study. In the perceptual identification test that followed, 5 studied items were presented very briefly together with 5 new items, and subjects were asked to identify the items. If a subject failed to identify the item correctly, the item was presented again with a longer exposure. This procedure was continued until the subject correctly identified the item. Both the small number of items and the repeated stimulus presentations (particularly in the case of the nonwords, which were harder to identify) may have encouraged normal subjects to retrieve study items explicitly (consciously) from memory. Indeed, in Cermak et al.'s (1985) study, amnesic patients did exhibit some degree of priming for nonwords. However, normal subjects outperformed amnesic patients (for amnesic patients, $18 \mathrm{msec}$ less exposure time was needed to identify previously presented nonwords, compared to new nonwords; for control subjects, 55 msec less exposure time was needed). This is the result that would be expected if normal subjects were able to extract some information while nonwords were being repeatedly presented and were then able to use declarative strategies (i.e., recall) to retrieve the nonwords that had been presented at study. In another study, nonword "priming" was measured in a task that used cued-recall instructions (Diamond \& Rozin, 1984), which would likely have put amnesic patients at a disadvantage (see Graf, Squire, \& Mandler, 1984).

In order to determine whether or not amnesic patients can acquire novel verbal information after a single encounter with the test material, we have reexamined nonword priming by using the benchmark perceptual identification paradigm. We attempted to reduce the possibility that normal subjects could invoke explicit memory strategies. First, we used a larger study set of words and nonwords than those in the previous studies. Second, we used a paradigm in which subjects were given only one brief presentation of the item at test, rather than multiple presentations.

\section{METHOD}

\section{Subjects}

Amnesic patients. Ten amnesic patients were tested. Four had alcoholic Korsakoff's syndrome (for computed tomography and magnetic resonance [MR] imaging findings, see Shimamura et al., 1988 [for Patients N.C., V.F., and P.N.]; Squire, Amaral, \& Press, 1990 [for Patients R.C. and P.N.]). Of the 6 other patients, two (W.I. and J.L.) had bilateral hippocampal pathology identified by MR imaging (Press, Amaral, \& Squire, 1989; Squire et al., 1990). Patients W.I. and J.L. became amnesic gradually during a period of about 2 years (for W.I., from 1983 to 1985; for J.L., from early 1985 to early 1987); their memory impairment has remained stable since that time. One patient (A.B.) became amnesic in 1976 following an anoxic episode during a cardiac arrest. Two patients (N.A. and M.G.) have diencephalic lesions confirmed by MR imaging. Patient N.A. became amnesic, primarily for verbal information, after a penetrating stab wound to the left diencephalic region 
Table 1

Description of Amnesic Patients

\begin{tabular}{|c|c|c|c|c|c|c|c|c|c|c|}
\hline \multirow[b]{2}{*}{ Subject } & \multirow[b]{2}{*}{ Age } & \multirow[b]{2}{*}{ Sex } & \multirow[b]{2}{*}{ Education } & \multirow[b]{2}{*}{ Etiology } & \multirow[b]{2}{*}{ WAIS-R IQ } & \multicolumn{5}{|c|}{ WMS-R } \\
\hline & & & & & & Attention & Verbal & Visual & General & Delay \\
\hline A.B. & 53 & $\mathbf{M}$ & 19 & Anoxia & 119 & 87 & 62 & 72 & 54 & $<50$ \\
\hline J.L. & 71 & $\mathbf{M}$ & 14 & Unknown & 116 & 122 & 73 & 83 & 74 & 58 \\
\hline L.J. & 53 & $\mathbf{F}$ & 12 & Unknown & 98 & 105 & 83 & 60 & 69 & $<50$ \\
\hline M.G. & 58 & $\mathbf{F}$ & 13 & $\begin{array}{l}\text { Thalamic } \\
\text { infarction }\end{array}$ & 111 & 113 & 89 & 84 & 86 & 63 \\
\hline N.A. & 52 & $\mathbf{M}$ & 13 & $\begin{array}{l}\text { Penetrating } \\
\text { brain injury }\end{array}$ & 120 & 102 & 67 & 89 & 68 & 71 \\
\hline N.C. & 47 & $\mathbf{F}$ & 12 & Korsakoff & 90 & 62 & 80 & 60 & 69 & $<50$ \\
\hline P.N. & 63 & $\mathbf{F}$ & 12 & Korsakoff & 88 & 81 & 77 & 73 & 67 & 53 \\
\hline R.C. & 74 & $\mathbf{M}$ & 9 & Korsakoff & 106 & 115 & 76 & 97 & 80 & 72 \\
\hline V.F. & 71 & $\mathbf{M}$ & 10 & Korsakoff & 103 & 101 & 78 & 72 & 72 & 66 \\
\hline W.I. & 77 & $\mathbf{M}$ & 12 & Unknown & 104 & 92 & 72 & 82 & 71 & 58 \\
\hline$M$ & 61.9 & & 12.6 & & 105.5 & 98.0 & 75.7 & 77.2 & 71.0 & 59.1 \\
\hline
\end{tabular}

Note-The WAIS-R (Wechsler Adult Intelligence Scale-Revised) Full Scale IQ and the five indices of the WMS-R (Wechsler Memory Scale-Revised) yield a mean score of 100 in the normal population with a standard deviation of 15. The WMS-R does not provide numerical scores for subjects who score below 50 . Therefore, values below $\mathbf{5 0}$ were scored as $\mathbf{5 0}$ in computing the means. Education is given in years.

in 1960 (Squire, Amaral, Zola-Morgan, Kritchevsky, \& Press, 1989; Teuber, Milner, \& Vaughan, 1968). Patient M.G. became amnesic in 1986 following a bilateral medial thalamic infarction. Finally, one patient (L.J.) became amnesic gradually between September 1988, and February 1989, without any known precipitating event. Her memory impairment has remained stable since that time. The present study was concerned with the overall performance of amnesic patients, and the patients are therefore presented as a single group.

A description of the 10 patients and their scores on standard memory tests appear in Tables 1 and 2 . In addition, immediate and delayed (12 $\mathrm{min}$ ) recall of a short prose passage averaged 5.4 and 0 segments, respectively. Free recall of 15 words (Rey auditory verbal learning test; Lezak, 1983; Rey, 1964) averaged 4.1, 4.8, $5.3,4.8$, and 5.1 across five successive trials, each of which consisted of a study phase and a test phase (i.e., 5 study/test trials). Recognition of 15 previously presented words and 15 new words presented one at a time, with instructions to make a yes/no choice, averaged $21.8,26.0,25.7,26.4$, and 27.1 correct responses across five successive study/test trials. The mean score on the Dementia Rating Scale (Mattis, 1976) was 133.2 points out of a possible 144 points, with an average total score of 114.5 for the portion of the test that does not assess memory (maximum $=119$ ). The mean score on the Boston Naming Test (Kaplan, Goodglass, \& Weintraub, 1983) was 55.0 (maximum $=60$; range: $48-59$ ). Scores for normal subjects on these same tests can be found elsewhere (Janowsky, Shimamura, Kritchevsky, \& Squire, 1989; Squire et al., 1990).

Control subjects. Fifteen normal subjects ( 8 men and 7 women) served as a control group for the amnesic patients. They were employees or volunteers at the Veterans Affairs Medical Center in San Diego, or members of the University of California, San Diego retirement community. All of the control subjects were native English speakers who were paid for their participation. None reported a history of alcohol or other drug abuse, head injury, or other neu-

Table 2

Performance on Standard Memory Tests

\begin{tabular}{ccccccc}
\hline Patientns & $\begin{array}{c}\text { Diagram } \\
\text { Recall }\end{array}$ & $\begin{array}{c}\text { Paired } \\
\text { Associates }\end{array}$ & $\begin{array}{c}\text { Word } \\
\text { Recall }(\boldsymbol{\%})\end{array}$ & $\begin{array}{c}\text { Word } \\
\text { Recognition (\%) }\end{array}$ & 50 Words & 50 Faces \\
\hline A.B. & 4 & $1-1-2$ & 33 & 83 & 32 & 33 \\
J.L. & 1 & $0-0-0$ & 40 & 93 & 31 & 20 \\
L.J. & 3 & $0-0-0$ & 40 & 93 & 37 & 40 \\
M.G. & 0 & $0-0-2$ & 33 & 71 & 30 & 34 \\
N.A. & 17 & $0-0-2$ & 49 & 93 & 34 & 42 \\
N.C. & 0 & $1-0-1$ & 23 & 71 & 31 & 37 \\
P.N. & 2 & $1-1-1$ & 29 & 83 & 27 & 38 \\
R.C. & 3 & $0-0-3$ & 19 & 85 & 37 & 30 \\
V.F. & 8 & $0-0-0$ & 27 & 91 & 27 & 31 \\
W.I. & 0 & $0-0-0$ & 29 & 85 & 31 & 30 \\
M & 3.8 & $0.3-0.2-1.1$ & 32.2 & 84.8 & 31.7 & 33.5 \\
Controls $(n=8)$ & 20.6 & $6.0-7.6-8.9$ & 71.0 & 97.0 & 41.1 & 38.1 \\
\hline
\end{tabular}

Note-The diagram recall score is based on delayed (12 $\mathrm{min}$ ) reproduction of the Rey-Osterrieth figure (Osterrieth, 1944; maximum score $=36$ ). The average score for copying the figure was 27.4 , a normal score (Kritchevsky, Squire, \& Zouzounis, 1988). The paired associate score is the number of word pairs recalled on three successive trials (maximum score $=10 /$ trial). The word recall score is the percentage of words recalled out of 15 across five successive study/test trials (Rey, 1964). The word recognition score is the percentage of words identified correctly across five successive study/test trial (yes/no recogntion of 15 new words and 15 old words). The score for words and faces is based on a 24-h recognition test of 50 words and 50 faces (modified from Warrington, 1984; maximum score $=50$, chance $=25$ ). The mean scores for normal subjects shown for these tests are from Squire and Shimamura (1986). Note that patient N.A. is not severely impaired on nonverbal memory tests, because his brain injury is primarily left unilateral. 
rological disorder. The 15 control subjects were matched to the amnesic patients with respect to age (64 years), education (14 years), and scores on the Information and Vocabulary subtests of the WAIS-R (control subjects $=21.7$ and 53.9, respectively; amnesic patients = 19.7 and 54.0, respectively). Immediate and delayed (12 $\mathrm{min}$ ) recall of a short prose passage averaged 6.7 and 5.5 segments, respectively.

\section{Materials}

A set of 40 five-letter words (mean frequency $=27.4$ per million; range: 1-100; Carroll, Davies, \& Richman, 1971) and 40 pronounceable, five-letter nonwords were first used to determine the appropriate duration of stimulus presentation for the perceptual identification test, as described below. The nonwords were derived from a separate set of $\mathbf{4 0}$ words having the same frequency range as the words used in the experiment. Nonwords were constructed by changing one or two letters in each of these 40 words to produce pronounceable, orthographically regular nonwords. The stimuli for the perceptual identification test consisted of 64 fiveletter words (mean frequency $=25.5$ per million; range: $1-100$ ) and 64 five-letter nonwords. An additional set of 10 four-letter words and 10 four-letter nonwords were used as practice items and were administered immediately prior to the perceptual identification test. Finally, a separate set of 32 five-letter words (mean frequency = 25.6) and 32 five-letter nonwords provided the distractor items for the recognition memory test as described below.

\section{Design and Procedure}

The experiment consisted of three phases: determination of the duration of stimulus presentation, a perceptual identification test, and a recognition memory test. The determination of stimulus duration was done in a separate session on a day prior to the perceptual identification and recognition memory tests (on average, 7 days earlier). All stimuli were presented on a Macintosh Plus computer, using MacLab Version 1.9R. Words and nonwords were presented at the center of the screen in 72-point (approximately 1.8-cm-high) uppercase block letters, subtending approximately $13.7^{\circ}$ of horizontal and $2.1^{\circ}$ of vertical visual angle. The examiner was sat next to the subject and recorded all responses verbatim. Response times were recorded via a voice-activated switch connected to the computer.

Determination of stimulus duration. Each subject was first tested to determine the presentation time that would permit briefly presented words and nonwords to be identified with approximately $50 \%$ accuracy. Words and nonwords were tested separately. Subjects were first instructed that words would be presented very briefly and that each word should be pronounced aloud. For each trial, a blank screen was in view for $2 \mathrm{sec}$ followed by an orientation signal (cross) at the center of the screen for $1 \mathrm{sec}$ prior to stimulus presentation. The orientation signal was then replaced by a word, which was presented for $100 \mathrm{msec}$. A mask, which consisted of a series of ampersands that encompassed the area of the screen occupied by the word, immediately replaced the word. The mask remained on the screen until the subject responded, at which time the next trial was automatically initiated. A total of four blocks of six trials each were presented in this way. The stimulus duration for each successive block was decreased when subjects identified more than 3 words in a six-trial block, and it was increased when subjects identified fewer than 3 words. Stimulus duration could be altered in 17-msec increments with a minimum duration of $33 \mathrm{msec}$. The administration of the four 6-word blocks resulted in two candidate exposure durations. One of these two durations was then selected for the perceptual identification test by comparing them in two additional 8-word blocks approximately $2 \mathrm{~min}$ after the final 6-word test. After all 40 words had been presented (four 6-word blocks and two 8-word blocks), a stimulus duration was selected that resulted as nearly as possible in $50 \%$ correct identification (the mean duration selected for all subjects was $49.8 \mathrm{msec}$ ).
The stimulus duration for nonwords was determined in the same way as for words, except that nonwords were first presented for $133 \mathrm{msec}$ instead of $100 \mathrm{msec}$. At the end of this procedure, the stimulus duration used for nonwords averaged $116.8 \mathrm{msec}$ across all subjects.

Perceptual identification test. The perceptual identification test was administered in four study/test blocks separated from each other by about $2 \mathrm{~min}$. Sixteen items were presented at each study phase, and 32 items were presented at each test phase. Across the four blocks, subjects studied 64 items and were tested with 128 items. Subjects were first given practice in the liking rating task that would be used in the study phase and were then given practice at identifying briefly presented words and nonwords.

The study phase of each study/test block involved the presentation of 8 words and 8 nonwords one at a time on the computer screen. The order of words and nonwords was random, with the constraint that no more than 3 words or nonwords appear consecutively. Subjects were asked to rate each item on a 1 to 5 scale according to how much they liked the item. Items remained on the screen until the subject responded by typing a number (1-5). A rating of 1 corresponded to dislike very much, and a rating of 5 corresponded to a rating of like very much. An index card with the rating scale printed on it remained in view during the presentation of all 16 items.

For half of the subjects, the study phase was followed after a 1min delay by a perceptual identification test for 16 words ( 8 old words and 8 new words) and then after another 1 -min delay by a separate perceptual identification test for 16 nonwords ( 8 old nonwords and 8 new nonwords). The remaining subjects received the test for the 16 nonwords first and then the test for the 16 words. The order of new and old items in each group of 16 items was random, with the constraint that each block of 8 items contain 4 old items and 4 new items. Also, the 4 old items in each 8 -item block were drawn equally from the first and second halves of the study list. Finally, no more than 3 new or old items were presented consecutively. The order of testing words or nonwords for each subject alternated across the four study/test blocks and was counterbalanced across subjects. In addition, there were two equivalent sets of the perceptual identification test. The studied items in one set served as the unstudied items in the other set. The assignment of test sets was counterbalanced across subjects.

Subjects were instructed that they would be shown words or nonwords very briefly and that they should try to read aloud each item as quickly and accurately as possible. Each trial began with a blank screen for $2 \mathrm{sec}$ followed by an orientation signal (cross) at the center of the screen for $1 \mathrm{sec}$. The orientation signal was then replaced by a word (or nonword), presented at the duration determined for that subject. A mask immediately replaced the stimulus. The next trial began automatically, immediately after the subject's response.

In summary, subjects studied 16 items (8 words and 8 nonwords) and were then given two perceptual identification tests: one involving 8 old words and 8 new words, and a second test involving 8 old nonwords and 8 new nonwords. This sequence occurred a total of four times, so that subjects studied a total of 32 words and 32 nonwords and were given perceptual identification tests involving the 32 old words, the 32 old nonwords, and equal numbers of new words and new nonwords.

Occasionally, the predetermined stimulus duration used to present words or nonwords to a particular subject did not result in identification of $50 \%$ of the new words or nonwords. In the $16 \%$ of the cases in which subjects correctly identified fewer than $13 \%$ or greater than $87 \%$ of the new words or nonwords in the first two blocks of the perceptual identification test, the stimulus duration was altered by $17 \mathrm{msec}$ for the remaining two study/test blocks.

Recognition test. Approximately 3 min after completion of the fourth study/test block of the perceptual identification test, subjects received a 32-item, two-alternative, forced-choice recognition test. The correct items were words and nonwords ( 16 items each) that had appeared on both the study list and the perceptual identifica- 
tion test. The items were drawn equally from the four study/test blocks. One correct item and 1 of the 32 distractor items appeared together on the computer screen, one above the other. The subject was instructed to indicate which of the 2 items had appeared during the experiment by typing one of two keys (labeled "top" and "bottom'). The correct item was presented equally often in each spatial position.

\section{RESULTS}

\section{Perceptual Identification}

The percentage of correctly identified words and nonwords is shown in Figure 1. As intended, both normal subjects and amnesic patients identified unstudied items with approximately $50 \%$ accuracy (words, $56.6 \%$ for amnesic patients, $58.3 \%$ for control subjects; nonwords, $45.7 \%$ for amnesic patients, $44.5 \%$ for control subjects). None of these values differed significantly from $50 \%$ ( $t \mathrm{~s}<1.4, p \mathrm{~s}>.20$ ). Note that the stimulus durations used to present words and nonwords were similar for the two subject groups (amnesic patients, $53.1 \mathrm{msec}$ for words and $134.3 \mathrm{msec}$ for nonwords; control subjects, $49.9 \mathrm{msec}$ for words and $106.8 \mathrm{msec}$ for nonwords) $[t \mathrm{~s}(23)<1.1, p \mathrm{~s}>.30]$.

Repetition priming was measured as an improved ability to identify correctly the words and nonwords that had been recently studied. The results from Figure 1 were analyzed with an analysis of variance (ANOVA) involving three factors (group, word/nonword, and old/new). The important finding was that both subject groups identified more studied items than unstudied items - that is, they exhibited priming $[F(1,23)=117.3, p<.001]$. Both groups also identified correctly more words than nonwords independently of whether they had been studied $[F(1,23)=29.5, p<.001]$. None of the other main effects or interactions were significant (all $F \mathrm{~s}<1.0$ ). In other words, priming was similar for the two groups of subjects and similar for words and nonwords.

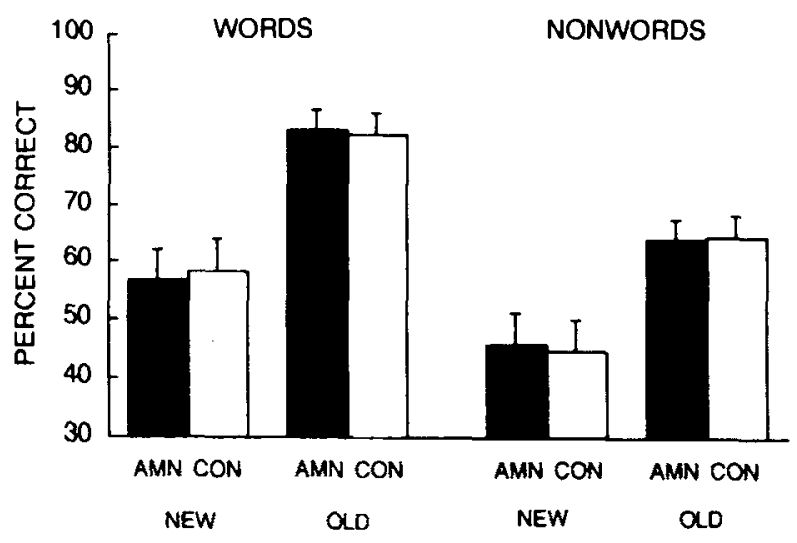

Figure 1. Performance of amnesic patients (AMN; $n=10)$ and control subjects (CON; $n=15$ ) on the perceptual identification test. Studied items (old) were presented once prior to the perceptual identification test. Unstudied items (new) had not been presented previously.

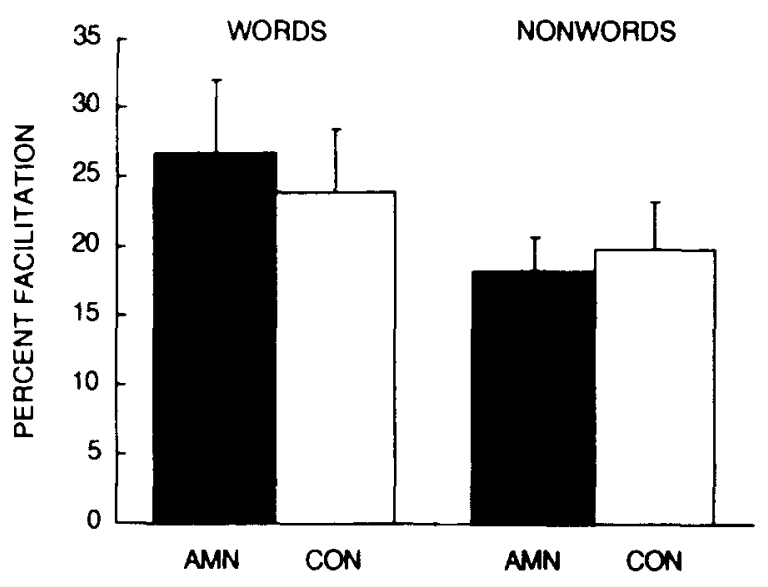

Figure 2. Facilitation scores for amnesic patients (AMN) and control subjects (CON) on the perceptud identification test. Facilitation was measured by subtracting the percent of correctly identifled new items from the percent of correctly identified old items, as shown in Figure 1. Amnesic patients exhibited normal perceptual priming for both words and nonwords.

\section{Facilitation Scores}

The findings are presented in a different way in Figure 2 by subtracting for each subject the percentage of correctly identified new words (or nonwords) from the percentage of correctly identified old words (or nonwords). In summary, amnesic patients exhibited entirely normal repetition priming for both words and nonwords (for words and nonwords: amnesic patients, $26.6 \%$ and $18.2 \%$, respectively; control subjects, $24.0 \%$ and $19.9 \%$, respectively). The benefit of prior experience was highly reliable across subjects. Every amnesic patient and all but 1 control subject correctly identified more old words and nonwords than new words and nonwords.

\section{The Basis for Priming of Nonwords}

We next explored the possibility that the priming effect observed for nonwords might depend on perceived similarity between the nonwords and real words. We first asked whether the priming effect might have depended on a subset of nonwords that were phonetically similar to real words. This possibility was tested by removing from the analysis all nonwords that were rated as phonetically similar to real words by more than 5 of 19 normal subjects. These 19 raters did not otherwise participate in the experiment. By this criterion, 12 of the 64 nonwords were identified as phonetically similar to real words (e.g., rigle, scane). However, the results did not change when these 12 nonwords were eliminated from the data analysis. The average scores for each group remained within $2.3 \%$ of their previous values, and amnesic patients and control subjects continued to exhibit similar benefits from prior presentation of nonwords (facilitation scores: amnesic patients, $16 \%$; control subjects, $20 \%$ ) $[t(23)=0.9, p>.30]$. Therefore, it is unlikely that the priming effect observed for nonwords is related to per- 
ceived phonetic similarity between nonwords and real words.

We also asked whether the priming effect could have depended on the extent to which nonwords appeared to be visually similar to real words. If so, more priming should have occurred for nonwords that were orthographically similar to real words than for nonwords that were orthographically irregular. An approach to this issue was suggested by the finding that orthographically regular nonwords can be read more quickly than orthographically irregular nonwords (Forster \& Chambers, 1973; Frederiksen \& Kroll, 1976; Glushko, 1979). We therefore attempted to select regular and irregular nonwords from our set of nonwords and to examine the magnitude of the priming effect for nonwords of each type. To select orthographically regular and irregular nonwords, we presumed that irregular nonwords would be more difficult to identify than regular nonwords when they were initially presented. Accordingly, we divided all 64 nonwords into two equal groups based on the percent correct score associated with each nonword when it was presented as a new item in the perceptual identification test. The results were that the nonwords easiest to identify, when they were presented as new items on the perceptual identification test, were identified correctly $61.0 \%$ of the time. These same nonwords were identified correctly $67.2 \%$ of the time when they were presented as old items on the perceptual identification test $[t(31)=2.4, p<.05]$. The nonwords that were the hardest to identify when they were presented as new items were identified correctly $28.8 \%$ of the time. These items were identified correctly $60.5 \%$ of the time when they were presented as old items $[t(31)$ $=11.4, p<.001]$.

It is difficult to compare these two levels of priming, because of the likelihood that a ceiling effect limited how well items could be identified. Nevertheless, substantial priming did occur for nonwords that were initially difficult to identify $(28.8 \%$ identification when they were new, $60.5 \%$ when they were old). If we are correct in presuming that the nonwords hardest to identify initially were those that were orthographically most different from real words, it is clear that priming for nonwords need not depend significantly on the visual similarity between nonwords and real words.

\section{Immediate Versus Delayed \\ Perceptual Identification Tests}

We next examined the strength of the priming effect as a function of whether words (or nonwords) were tested immediately after they were presented in the study phase or, in half the cases, after the approximately $5 \mathrm{~min}$ required to test nonwords (or words). Delaying the perceptual identification test did not affect priming. For amnesic patients, the overall facilitation scores for words on immediate and delayed tests were $26 \%$ and $27 \%$, respectively; for nonwords, $20 \%$ and $16 \%$. For control subjects, the corresponding values for words were $28 \%$ and $20 \%$; for nonwords, $19 \%$ and $20 \%$. These facilitation scores were submitted to an analysis of variance (group, word/nonword, and immediate/delayed). None of the main effects or interactions were significant $\left[F_{\mathrm{s}}(1,23)<\right.$ $1.0, p>.30]$. Thus, the priming effects observed in the present study were highly stable for at least $5 \mathrm{~min}$ after item presentation.

\section{Liking Ratings}

Amnesic patients and control subjects provided similar liking ratings, and both groups rated words more highly than nonwords. (Because of an equipment malfunction, liking ratings and study times for 1 amnesic patient were unavailable, and this analysis was therefore based on 9 of the 10 amnesic patients). The mean ratings given by amnesic patients for words and nonwords were 3.8 and 1.8, respectively; for control subjects, 3.9 and 2.0 [group, $F(1,22)=1.3, p>.20$; word vs. nonword, $F(1,22)=107.6, p<.001 ;$ group $\times$ word/nonword, $F(1,22)<1.0, p>.20]$.

\section{Response Times}

Amnesic patients took somewhat longer than control subjects did to make liking ratings, although the difference did not reach significance (for amnesic patients, words, $1,923 \mathrm{msec}$; nonwords, $2,156 \mathrm{msec}$; for control subjects, words, $1,560 \mathrm{msec}$; nonwords, $1,730 \mathrm{msec}$ ) [group, $F(1,22)=3.2, p<.09$; words vs. nonwords, $F(1,22)=10.1, p<.01$; group $\times$ word/nonword, $F(1,22)<1.0, p>.20]$. Across subjects, the time that words or nonwords remained on the screen during the presentation phase did not correlate with facilitation scores-that is, with the advantage of old items over new items on the subsequent identification test $(p>.20)$.

Table 3 shows response times for the new and old items that were correctly identified on the perceptual identification test. An ANOVA with three factors (group, word/nonword, and old/new) indicated that subjects identified old words and old nonwords more quickly than new words and new nonwords [old vs. new, $F(1,22)=8.9$, $p<.01]$. None of the other main effects or interactions

Table 3

Response Times (in Milliseconds) for Correctly Identified Items on the Perceptual Identification Test

\begin{tabular}{lcccc}
\hline \multirow{4}{*}{ Item } & \multicolumn{2}{c}{ Amnesic Patients } & \multicolumn{2}{c}{ Control Subjects } \\
\cline { 2 - 4 } \cline { 3 - 5 } & $M$ & SEM & $M$ & SEM \\
\hline Words & 770 & 100 & 867 & 86 \\
Nonwords & 694 & 52 & 820 & 83 \\
& & Studied Items & & \\
Words & 675 & 52 & 741 & 45 \\
Nonwords & 674 & 39 & 755 & 79 \\
& & Facilitation & & \\
Words & 95 & 51 & 126 & 49 \\
Nonwords & 20 & 38 & 64 & 30 \\
\hline
\end{tabular}

Note-Response times are the means of the median response times of each subject. Facilitation was calculated by subtracting the response times for studied items from the respone times for unstudied items. Response times were unavailable for 1 amnesic patient. Therefore, response times for amnesic patients are based on results from 9 patients. 
approached significance $(F \mathrm{~s}<1.0)$. Separate analyses showed that the facilitation scores for the two groups were not measurably different for either words or nonwords $(F<1.0)$. Nevertheless, the facilitation scores for response times were numerically lower for amnesic patients than for control subjects, and the facilitation score obtained by the amnesic patients for nonwords was not significantly different from zero $(p>.10)$.

\section{Recognition Memory}

In contrast to the finding that amnesic patients exhibited normal repetition priming for both words and nonwords, amnesic patients were impaired on the recognition memory test. They correctly recognized $71 \%$ of the words and $74 \%$ of the nonwords from the perceptual identification test. Control subjects correctly recognized $84 \%$ of the words and $87 \%$ of the nonwords [group, $F(1,23)=13.7$, $p<.001$; group $\times$ stimulus type, $F<1$ ]. The finding that the amnesic patients performed well above chance $(50 \%)$ on the two-choice recognition memory test is consistent with previous findings that recognition tests provide a very sensitive method for detecting residual memory in otherwise severely amnesic patients, especially when the retention interval is short (Cohen \& Squire, 1980; Hirst, Johnson, Phelps, \& Volpe, 1988; Mayes, Meudell \& Neary, 1980; Musen et al., 1990) (also see Table 2).

\section{Independence of Perceptual Identification and Recognition Memory}

Despite the fact that recognition memory was above chance levels, recognition performance was independent of perceptual identification performance. We calculated for all subjects the probability of identifying a word or nonword correctly on the perceptual identification test as a function of whether that same item was recognized or not on the recognition memory test. This analysis was carried out for the 16 words and 16 nonwords that appeared on both tests and for all 15 control subjects and 7 of the amnesic patients (the item-by-item data were unavailable for 3 of the amnesic patients). The probability of identifying an item correctly on the perceptual identification test, given correct recognition of the item, was .74. The probability of identifying an item correctly, given failure to recognize the item, was .78. The independence of perceptual identification and recognition memory was also indicated by the nonsignificant chi-square $\left(\chi^{2}=.73\right)$, which was calculated from the total number of correct and incorrect identification and recognition choices cumulated across all subjects.

\section{DISCUSSION}

In agreement with previous studies that tested perceptual identification of words in normal subjects (Feustel et al., 1983; Jacoby, 1983a, 1983b; Jacoby \& Dallas, 1981; Rueckl, 1990; Salasoo et al., 1985; Whitlow \& Cebollero, 1989) or amnesic patients (Cermak et al., 1985;
Cermak et al., 1991), both subject groups were facilitated in identifying words that had been previously presented. The important finding in the present study was that amnesic patients and control subjects were similarly facilitated in identifying previously presented nonwords. Musen and Squire (1991b) demonstrated that amnesic patients were also normal at developing a reading skill for nonwords across multiple repetitions. However, to our knowledge, the present study is the first demonstration in amnesic patients of entirely normal priming for nonwords after a single study trial. The facilitatory effect for words was numerically larger for words than for nonwords, but this effect was not significant. The finding for nonwords indicates that priming can involve the acquisition of new information, not simply the activation of preexisting representations.

We considered whether priming of nonwords might have been based on activation of words that were phonologically or orthographically similar to the nonwords. If priming of nonwords had occurred through activation of words, then one would expect word-like nonwords to have resulted in more priming than nonwords that were not similar to real words. However, we found no evidence for an advantage of word-like nonwords over other nonwords. First, when nonwords judged to be phonologically similar to real words were eliminated from the data analysis, the magnitude of the priming effect was virtually unchanged. Second, the nonwords that were harder to identify when they were first presented, and that were therefore presumed to be less orthographically regular (i.e., less word-like), resulted in even more priming than nonwords that were easy to identify when they were first presented. Thus, priming of nonwords is unlikely to have resulted from neighborhood effects (i.e., their similarity to real words).

Cermak et al. (1991) reported that the amount of priming for nonwords was influenced by their phonological similarity to real words. They measured perceptual identification priming for words, nonwords, and pseudohomonyms (items that are orthographically unfamiliar but phonologically familiar; e.g., phaire). When nonwords, words, and pseudohomonyms were presented for study in a mixed list, amnesic patients exhibited impaired priming for both nonwords and pseudohomonyms. Amnesic patients did, however, exhibit normal priming for pseudohomonyms when they were presented at study in a single list. Our study resembles the mixed list condition of the study by Cermak et al. (1991), because 12 pseudohomonyms were presented together with the other nonwords in one list. Yet we found normal priming for both nonwords and phonologically word-like nonwords (pseudohomonyms).

We suggest that the difference between the two studies arises from the fact that the control subjects in the other study relied on explicit memory to perform the perceptual identification task. This possibility was also acknowledged by Cermak et al. (1991). Only eight items were presented at study and test, and items at test were 
presented repeatedly, with increasing exposure time, until identification was successful. In such a paradigm, it seems reasonable to expect that subjects would draw on explicit memory to recall the study words. Moreover, explicit memory would be expected to contaminate nonword priming more than word priming because the number of presentations was larger for nonwords, and the additional repetitions given for nonwords would provide normal subjects more opportunities to access explicit memory. We also suggest that control subjects were able to rely on explicit memory in an earlier similar study, the only other study known to us in which amnesic patients were reported to be impaired on a priming test involving the perceptual identification of nonwords (Cermak et al., 1985). Finally, in one additional early study involving the completion of words and nonwords from three-letter stems (Diamond \& Rozin, 1984), explicit memory was also likely to have been used by normal subjects because the test was presented as a cued-recall paradigm and subjects were instructed to retrieve items from memory.

In our study, control subjects had less opportunity to rely on explicit memory because the study and test sets were large ( 16 and 32 items, respectively), test items were presented only once, and the instruction was simply that the subject should try to read each item that was presented. The results were that equivalent word and nonword priming occurred in both amnesic patients and normal subjects, despite the fact that amnesic patients were impaired relative to normal subjects on a recognition memory test involving the same words and nonwords that served as old items on the perceptual identification test.

The finding that amnesic patients exhibited normal priming of nonwords suggests that perceptual priming is preserved in amnesia and that it need not depend on activation of preexisting representations of the test items. Priming could involve activation of preexisting representations of letters or other features that are common to both words and nonwords. But priming does not require a preexisting representation of an entire item. This conclusion agrees with recent findings of normal priming for novel nonverbal material in amnesia (Gabrieli et al., 1990; Musen \& Squire, 1991a; Schacter et al., 1991).

Perceptual priming refers to information that is processed presemantically. In contrast, semantic or conceptual priming refers to facilitation in processing information based on access to meaning. Semantic priming tasks that have been studied in amnesia include word association priming (Shimamura \& Squire, 1984; Verfaellie, Cermak, Blackford, \& Weiss, 1990), tasks of category priming (Gardner, Boller, Moreines, \& Butters, 1973; Graf, Shimamura, \& Squire, 1985), and lexical decision tasks (Glass \& Butters, 1985; Gordon, 1988; Smith \& Oscar-Berman, 1990). In all but one of these studies (Smith \& Oscar-Berman, 1990), amnesic patients have been found to exhibit normal semantic priming. Specifically, when semantic priming of nonwords was tested in a lexical decision paradigm, amnesic patients were impaired (but see Gordon, 1988). Thus, in the semantic priming tasks that amnesic patients perform normally, access to preexisting information seems to be required.

The lexical decision task has been used to study semantic priming with the assumption that the decision regarding whether an item is a word or a nonword requires access to semantic representations. It is possible that during the first presentation of a nonword, normal subjects make a link between the nonword and its lexical status (i.e., that it is not a word). This new memory representation may require the joining of two units of information (i.e., the link between the nonword and its lexical status), and such a conjunction may be difficult to establish in amnesic patients, especially in a single trial.

Recent studies with normal subjects provide some clues about the neural bases of priming. First, in divided visual field studies, more word-stem completion priming has occurred when word stems have been presented to the left visual field (right hemisphere) than when they have been presented to the right visual field (left hemisphere) (Marsolek, Kosslyn, \& Squire, in press). The right hemisphere advantage appeared only when the items were presented at study and test in the same modality and in the same letter case. Thus, priming based on form-specific representations seems to involve the right hemisphere more than the left. Second, a recent functional anatomical study of word-stem-completion priming using positron emission tomography (PET) provided direct evidence for the involvement of the right hemisphere and in addition showed that priming depends on changes in posterior cortex (Squire, Ojemann, Miezin, Petersen, Videen, \& Raichle, in press). In that study, there was a reduction in blood flow in a region of right extrastriate cortex during wordstem-completion priming, relative to a baseline wordstem-completion condition in which priming could not $\alpha$ cur because none of the possible word completions had been presented for study. The finding of reduced activity in right posterior cortex during priming suggests that, for a time after a perceptual stimulus has been presented, less neural activity is required to process the same stimulus. This observation thus suggests a mechanism to account for the key feature of priming-that less information is needed to perceive and identify a stimulus accurately the second time it is presented. For example, in our study, more old words and nonwords were identified correctly than were new words and nonwords, even though new and old items were presented at exactly the same exposure duration.

It seems likely that perceptual identification priming of words, like word-stem-completion priming, depends on changes in posterior cortex. The task requires only that items be identified, not that they be understood. However, it is not yet clear whether perceptual identification priming resembles word-stem-completion priming with respect to the importance of form-specific mechanisms in the right hemisphere. One would expect that, to the extent that perceptual identification is advantaged by maintaining the same modality and typecase across study and test, the right hemisphere should be important for performing the task 
(for varying results in perceptual identification following changes in the appearance of the stimuli, see Graf \& Ryan, 1990; Jacoby \& Hayman, 1987). The extent to which form-specific mechanisms in the right hemisphere are important for word priming can be expected to vary, depending on the specific conditions of the experiment.

Indeed, other areas of the cortex are active during the reading of words and nonwords. In another PET study, increased blood flow was observed in the left posterior cortex during the reading of words and pronounceable nonwords but not during the reading of nonpronounceable nonwords and nonletter shapes (Petersen, Fox, Snyder, \& Raichle, 1990). This finding, together with the finding that word-stem completion is neither modalityspecific nor typecase-specific when word stems are presented to the left hemisphere (Marsolek et al., in press), suggests that the left posterior locus is specialized for the abstract processing of words, not for form-specific processing. It has been suggested that the left-hemisphere word-form area is a locus for perceptual priming of words (Schacter, 1990; Tulving \& Schacter, 1990). This possibility is not inconsistent with the idea that the right hemisphere is also important for perceptual priming. Indeed, it is possible that perceptual priming can be supported by any of multiple cortical areas in extrastriate cortex that are involved in the processing of visual information (Felleman \& Van Essen, 1991; Kaas, 1989; Ungerleider \& Mishkin, 1986; Zeki \& Shipp, 1988). Which areas support priming in any particular case should depend on task demands and on the specific characteristics of the stimuli. Amnesic patients perform normally on these tasks because perceptual priming reflects changes in early-stage processing systems that operate prior to and independently of the systems required for establishing declarative memory.

In summary, the present study provides strong confirmation of the idea that implicit memory can support the rapid acquisition of new perceptual information, probably in the posterior cortex. The finding of normal priming for nonwords in amnesia agrees with earlier findings in amnesic patients of normal nonword priming after multiple study presentations (Musen \& Squire, 1991b) and normal priming of nonverbal material (Gabrieli et al., 1990; Musen \& Squire, 1991a; Schacter et al., 1991). Amnesic patients are just as able to form new perceptual representations as normal subjects are, and they do so without depending on explicit memory.

\section{REFERENCES}

Bentin, S., \& Moscovitch, M. (1988). The time course of repetition effects for words and unfamiliar faces. Journal of Experimental Psychology: General, 117, 148-160.

Benzing, W., SourRe, L. R. (1989). Preserved learning and memory in amnesia: Intact adaptation-level effects and learning of stereoscopic depth. Behavioral Neuroscience, 103, 548-560.
Brooks, D. N., BAdDeleY, A. (1976). What can amnesic patients leam? Neuropsychologia, 14, 111-122.

Butrers, N., \& Stuss, D. T. (1989). Diencephalic amnesia. In F. Boller \& J. Grafman (Eds.), Handbook of neuropsychology (pp. 107-148). Amsterdam: Elsevier.

Carroll, J. B., Davies, P., Richman, B. 1971. Word frequency book. New York: American Heritage.

Cermak, L. S., Talbot, N., Chandler, K., \& Wolbarst, L. R. (1985). The perceptual priming phenomenon in amnesia. Neuropsychologia, 23, 615-622.

Cermak, L. S., Verfaelue, M., Milberg, W., Letourneau, L., - BlACKFord, S. (1991). A further analysis of perceptual identification priming in alcoholic Korsakoff patients. Neuropsychologia, 29, 725-736.

Cohen, N. J., a Squire, L. R. (1980). Preserved leaming and retention of pattern analyzing skill in amnesia: Dissociation of knowing how and knowing that. Science, 210, 207-209.

Damasio, A. R., Graff-Radpord, N. R., Eslinger, P. J., Damasio, H., Kassell, N. (1985). Amnesia following basal forebrain lesions. Archives of Neurology, 42, 263-271.

Diamond, R., Rozin, P. (1984). Activation of existing memories in anterograde amnesia. Joumal of Abnormal Psychology, 93, 98-105.

Felleman, D., \& VanEssen, D. (1991). Distributed hierarchical processing in primate cerebral cortex. Cerebral Cortex, 1, 1-47.

Feustel, T. C., Shiffrin, R. M., * Salasoo, A. (1983). Episodic and lexical contributions to the repetition effect in word identification. Journal of Experimental Psychology: General, 112, 309-346.

Forster, K. I., \& Chambers, S. M. (1973). Lexical access and naming time. Joumal of Verbal Leaming \& Verbal Behavior, 12, 627-635.

Frederiksen, J. R., \& Kroll, J. F. (1976). Spelling and sound: Approaches to the internal lexicon. Journal of Experimental Psychology: Human Perception \& Pefformance, 2, 361-379.

Gabriel, J. D. E., Milberg, W., Keane, M. M., * Corkin, S. (1990). Intact priming of patterns despite impaired memory. Neuropsychologia, 28, 417-427.

Gardner, H., Boller, F., Moreines, J., Butters, N. (1973). Retrieving information from Korsakoff patients: Effects of categorical cues and reference to the task. Conex, 9, 165-175.

Glass, A. L., Butrers, N. L. (1985). The effects of associations and expectations on lexical decision making in normals, alcoholics, and alcoholic Korsakoff patients. Brain \& Cognition, 4, 465-476.

Glushko, R. J. (1979). The organization of activation of orthographic knowledge in reading aloud. Joumal of Experimental Psychology: Human Perception \& Performance, 5, 674-690.

Gordon, B. (1988). Preserved learning of novel information in amnesia: Evidence for multiple memory systems. Brain \& Cognition, 7 , 257-282.

GraF, P., \& RYA, L. (1990). Transfer-appropriate processing for implicit and explicit memory. Journal of Experimental Psychology: Learning. Memory, \& Cognition, 16, 978-992.

Graf, P., Shimamura, A. P., * Squire, L. R. (1985). Priming across modalities and priming across category levels: Extending the domain of preserved function in amnesia. Journal of Experimental Psychology: Learning, Memory, \& Cognition, 11, 386-396.

Graf, P., Squire, L. R., Mandler, G. (1984). The information that amnesic patients do not forget. Joumal of Experimental Psychology: Leaming, Memory, \& Cognition, 10, 164-178.

Graff-Radford, N. R., Tranel, D., Van Hoesen, G. W., Brandt, J. (1990). Diencephalic amnesia. Brain, 113, 1-25.

Hintzman, D. (1990). Human learning and memory: Connections and dissociations. Annual Review of Psychology, 41, 109-139.

Hirst, W., Johnson, M. K., Phelps, E. A., Volpe, B. T. (1988). More on recognition and recall in amnesics. Joumal of Experimental Psychology: Leaming, Memory, \& Cognition, 14, 758-762.

JACOBY, L. L. (1983a). Perceptual enhancement: Persistent effects of an experience. Journal of Experimental Psychology: Leaming, Memory, \& Cognition, 9, 21-38. 
JACOBY, L. L. (1983b). Remembering the data: Analyzing interactive processes in reading. Journal of Verbal Learming \& Verbal Behavior, 22, 485-508.

JACOBY, L. L., \& DALLAS, M. (1981). On the relationship between autobiographical memory and perceptual learning. Joumal of Experimental Psychology: General, 3, 306-340.

JACOBY, L. L., HAYMAN, C. A. G. (1987). Specific visual transfer in word identification. Joumal of Experimental Psychology: Learming, Memory, \& Cognition, 13, 456-463.

Janowsky, J. S., Shimamura, A. P., Kritchevsky, M., \& SQuire, L. R. (1989). Cognitive impairment following frontal lobe damage and its relevance to human amnesia. Behavioral Neuroscience, 103, 548-560.

Johnson, M. K., KIM, J. K., \& RISSE, G. (1985). Do alcoholic Korsakoff's syndrome patients acquire affective reactions? Journal of Experimental Psychology: Learning, Memory, \& Cognition, 11, 22-36.

KAAS, J. (1989). Why does the brain have so many visual areas? Journal of Cognitive Neuroscience, 1, 121-135.

Kaplan, E. F., Goodglass, H., \& Weintraub, S. (1983). The Boston Naming Test. Philadelphia: Lea \& Febiger.

KERSTEEN-TUCKER, Z. (1991). Long-term repetition priming with symmetrical polygons and words. Memory \& Cognition, 19, 37-43.

Kritchevsky, M., Squire, L. R., \& Zouzounis, J. A. (1988). Transient global amnesia: Characterization of anterograde and retrograde amnesia. Neurology, 38, 213-219.

LEZAK, M. (1983). Neuropsychological assessment. New York: Oxford University Press.

MANDler, G. (1980). Recognizing: The judgment of previous occurrence. Psychological Review, 87, 252-271.

MARSOlek, C. J., Kosslyn, S. M., SQUIRE, L. R. (in press). Formspecific visual priming in the right cerebral hemisphere. Journal of Experimental Psychology: Learning, Memory, \& Cognition.

MatTIS, S. (1976). Dementia Rating Scale. In R. Bellack \& B. Keraso (Eds.), Geriatric psychiatry (pp. 77-121). New York: Grune \& Stratton.

Mayes, A., Meudell, P., \& Neary, D. (1980). Do amnesics adopt inefficient encoding strategies with faces and random shapes? Neuropsychologia, 18, 527-540.

MoNSELl, S. (1985). Repetition and the lexicon. In A. W. Ellis (Ed.), Progress in the psychology of language (pp. 147-195). New Jersey: Erlbaum.

MORTON, J. (1969). Interaction of information in word recognition. Psychological Review, 76, 165-178.

MoRTON, J. (1979). Facilitation in word recognition: Experiments causing change in the logogen models. In P. A. Kolers, M. E. Wrolstad, \& H. Bouma (Eds.), Processing of visible language (pp. 259-268). New York: Plenum.

Moscovitch, M. (1982). Multiple dissociations of function in amnesia. In L. Cermak (Ed.), Human memory and amnesia (pp. 337-370). Hillsdale, NJ: Erlbaum.

MuSEN, G., \& SQuIRE, L. R. (1991a). Nonverbal priming in amnesia. Manuscript submitted for publication.

MUSEN, G., SQUIRE, L. R. (1991b). Normal acquisition of novel verbal information in amnesia. Journal of Experimental Psychology: Leaming, Memory, \& Cognition.

Musen, G., Shimamura, A. P., Squire, L. R. (1990). Intact textspecific reading skill in amnesia. Journal of Experimental Psychology: Learning, Memory, \& Cognition, 16, 1068-1076.

Musen, G. \& Treisman, A. (1990). Implicit and explicit memory for visual patterns. Journal of Experimental Psychology: Learning, Memory, \& Cognition, 16, 127-137.

Nissen, M. J., \& Bullemer, P. (1987). Attentional requirements of learning: Evidence from performance measures. Cognitive Psychology, 19, 1-32.

OsterRIETh, P. A. (1944). Le test de copie d'une figure complexe [The test of copying a complex figure]. Archives de Psychologie, 30, 206-356.

Petresen, S. E., Fox, P. T., Snyder, A. Z., \& Raichle, M. E. (1990).
Activation of extrastriate and frontal cortical areas by visual words and word-like stimuli. Science, 249, 1041-1044.

Press, G., Amaral, D. G., \& SQUire, L. R. (1989). Hippocampal abnormalities in amnesic patients revealed by high-resolution magnetic resonance imaging. Nature, 341, 54-57.

ReY, A. (1964). L'examen clinique psychologie. Paris: Presses Universitaires de France.

Richardson-Klavehn, A., \& Bjork, R. A. (1988). Measures of memory. Annual Review of Psychology, 39, 475-542.

RuECKL, J. G. (1990). Similarity effects in word and pseudoword repetition priming. Joumal of Experimental Psychology: Learning, Memory, \& Cognition, 16, 374-391.

Salasoo, A., Shiffrin, R. M., \& Feustel, T. C. (1985). Building permanent codes: Codification and repetition effects in word identification. Journal of Experimental Psychology: General, 114, 50-77.

Scarborough, D. L., Cortese, C., \& Scarborough, H. S. (1977). Frequency and repetition effects in lexical memory. Journal of Experimental Psychology: Human Perception \& Performance, 3, 1-17.

SCHACTER, D. L. (1985). Multiple forms of memory in humans and animals. In N. Weinberger, G. Lynch, \& J. McGaugh (Eds.), Memory systems of the brain: Animal and human cognitive processes (pp. 351379). New York: Guilford.

SCHACTER, D. L. (1987). Implicit memory: History and current status. Journal of Experimental Psychology: Learning, Memory, \& Cognition, 13, 501-518.

SCHACTER, D. L. (1990). Perceptual representation systems and implicit memory: Toward a resolution of the multiple memory systems debate. In A. Diamond (Ed.), Development and neural bases of higher cognitive function (Annals of the New York Academy of Sciences: Vol. 608, pp. 543-571). New York: New York Academy of Sciences. SChacter, D. L., CoOper, L. A., \& Delaney, S. M. (1990). Implicit memory for unfamiliar objects depends on access to structural descriptions. Joumal of Experimental Psychology: General, 119, 5-24.

Schacter, D. A., Cooper, L. A., Tharan, M., Rubens, A. B. (1991). Preserved priming of novel objects in patients with memory disorders. Journal of Cognitive Neuroscience, 3, 118-131.

Shimamura, A. P. (1986). Priming effects in amnesia: Evidence for a dissociable memory function. Quarterly Journal of Experimental Psychology, 38A, 619-644.

Shimamura, A. P., Jernigan, T. L., \& SQuire, L. R. (1988). Korsakoff's syndrome: Radiological (CT) findings and neuropsychological correlates. Journal of Neuroscience, 8, 4400-4410.

Shimamura, A. P., \& Squire, L. R. (1984). Paired-associate learning and priming effects in amnesia: A neurospsychological analysis. Journal of Experimental Psychology: General, 113, 556-570.

Smith, M., Oscar-Berman, M. (1990). Repetition priming of words and pseudowords in divided attention in amnesia. Journal of Experimental Psychology: Learning, Memory, \& Cognition, 16, 1033-1042.

SQUiRE, L. R. (1982). The neuropsychology of human memory. Annual Review of Neuroscience, 5, 241-273.

Squire, L. R., Amaral, D. G., \& Press, G. A. (1990). Magnetic resonance measurements of hippocampal formation and mammillary nuclei distinguish medial temporal lobe and diencephalic amnesia. Journal of Neuroscience, 10, 3106-3117.

Squire, L. R., Amaral, D. G., Zola-Morgan, S., Kritchevsky, M., \& Press, G. A. (1989). Description of brain injury in the amnesic patient N.A. based on magnetic resonance imaging. Experimental Neurology, 105, 23-25.

SQuire, L. R., Frambach, M. (1990). Cognitive skill learning in amnesia. Psychobiology, 18, 109-117.

SQUIRE, L. R., MCKEE, R. (in press). The influence of prior events on cognitive judgments in amnesia. Journal of Experimental Psychology: Learning, Memory, \& Cognition.

Squire, L. R., Ojemann, J. G., Miezin, F. M., Petersen, S. E., VIDEEN, T. O., RAICHLE, M. E. (in press). Activation of the hippocampus in normal humans: A functional anatomical study of memory. Proceedings of the National Academy of Sciences, USA. 
SQuire, L. R., \& Shimamura, A. P. (1986). Characterizing amnesic patients for neurobehavioral study. Behavioral Neuroscience, 100 , 866-877.

SQuire, L. R., \& Zola-Morgan, M. (1991). The medial temporal lobe memory system. Science, 253, $1380-1386$.

Teuber, H.-L., Milner, B., Vaughan, H. G. (1968). Persistent anterograde amnesia after stab wound of the basal brain. Neuropsychologia, 6, 267-282.

TULVING, E. (1985). How many memory systems are there? American Psychologist, 40, 385-398.

Tulving, E., SCHacter, D. L. (1990). Priming and human memory systems. Science, 247, 301-306.

UNGERLEIDER, L., \& DEsImONE, R. (1986). Cortical connections of visual area MT in the Macaque. Journal of Comparative Neurology, $248,190-222$
Verfaelue, M., Cermax, L., Blackford, S., \& Weiss, S. (1990). Strategic and automatic priming of semantic memory in alcholic Korsakoff patients. Brain \& Cognition, 13, 178-192.

Warrington, E. K. (1984). Recognition Memory Test. Windsor: NFER-Nelson

Weiskruntz, L. (1987). Neuroanatomy of memory and amnesia: A case for multiple memory systems. Human Neurobiology, 6, 93-105.

Whitlow, J. W., JR., Cebollero, A. (1989). The nature of word frequency effects on perceptual identification. Joumal of Experimental Psychology: Learning. Memory, \& Cognition, 15, 643-656.

ZEKI, S., \& SHIPP, S. (1988). The functional logic of cortical connections. Narure, 325, 311-317.

(Manuscript received September 16, 1991; revision accepted for publication September 30, 1991.) 